Article type : Primary Research Articles

Paper type: Primary Research Article

\title{
Dominance-diversity relationships in ant communities differ with invasion
}

Running head: global dominance-diversity relationships

Xavier Arnan ${ }^{1 *}$, Alan N. Andersen ${ }^{2}$, Heloise Gibb ${ }^{3}$, Catherine L. Parr ${ }^{4}$, Nathan J. Sanders ${ }^{5}$, Robert R. Dunn ${ }^{6}$, Elena Angulo ${ }^{7}$, Fabricio B. Baccaro ${ }^{8}$, Tom R. Bishop ${ }^{9}$, Raphaël Boulay ${ }^{10}$, Cristina Castracani ${ }^{11}$, Xim Cerdá ${ }^{7}$, Israel Del Toro ${ }^{12}$, Thibaut Delsinne ${ }^{13}$, David A. Donoso ${ }^{14}$, Emilie K. Elten ${ }^{15}$, Tom M. Fayle ${ }^{16}$, Matthew C. Fitzpatrick ${ }^{17}$, Crisanto Gómez ${ }^{18}$, Donato A. Grasso $^{11}$, Blair F. Grossman ${ }^{3}$, Benoit Guénard ${ }^{19}$, Nihara Gunawardene ${ }^{20}$, Brian Heterick ${ }^{20}$, Benjamin D. Hoffmann ${ }^{21}$, Milan Janda ${ }^{16,22}$, Clinton N. Jenkins ${ }^{23}$, Petr Klimes ${ }^{16,24}$, Lori Lach $^{25}$, Thomas Laeger ${ }^{26}$, Maurice Leponce ${ }^{27}$, Andrea Lucky ${ }^{28}$, Jonathan Majer ${ }^{29}$, Sean Menke $^{30}$, Dirk Mezger ${ }^{31}$, Alessandra Mori ${ }^{11}$, Jimmy Moses ${ }^{16,24}$, Thinandavha Caswell Munyai $^{32}$, Omid Paknia ${ }^{33}$, Martin Pfeiffer ${ }^{34}$, Stacy M. Philpott ${ }^{35}$, Jorge L.P. Souza ${ }^{36,37}$, Melanie Tista ${ }^{38}$, Heraldo L. Vasconcelos ${ }^{39}$ \& Javier Retana ${ }^{1,40}$

This article has been accepted for publication and undergone full peer review but has not been through the copyediting, typesetting, pagination and proofreading process, which may lead to differences between this version and the Version of Record. Please cite this article as doi: $10.1111 /$ gcb.14331

This article is protected by copyright. All rights reserved. 
${ }^{1}$ CREAF, Cerdanyola del Vallès, Catalunya, Spain

${ }^{2}$ Research Institute for the Environment and Livelihoods, Charles Darwin University, NT 0909, Australia

${ }^{3}$ Department of Ecology, Evolution and the Environment, La Trobe University, Melbourne, Victoria 3086, Australia

${ }^{4}$ Department of Earth, Ocean and Ecological Sciences, University of Liverpool, Liverpool L69 3GP, UK

${ }^{5}$ Environmental Program, Rubenstein School of Environment and Natural Resources, University of Vermont, Burlington, VT 05405, USA

${ }^{6}$ Department of Applied Ecology, North Carolina State University, Raleigh, NC 27695, USA

${ }^{7}$ Estación Biológica de Doñana CSIC, calle Américo Vespucio 26, 41092 Sevilla (Spain)

${ }^{8}$ Departamento de Biologia, Universidade Federal do Amazonas, Manaus, 69080-900, Brazil

${ }^{9}$ Centre for Invasion Biology, Department of Zoology and Entomology, University of Pretoria, Pretoria, 0002, South Africa

${ }^{10}$ Institute of Insect Biology, University François Rabelais of Tours, 37200 Tours, France

${ }^{11}$ Department of Chemistry, Life Sciences and Environmental Sustainability, University of Parma, Parco Area delle Scienze, 11/a, 43124 Parma, Italy

${ }^{12}$ Biology Department, Lawrence University, Appleton Wisconsin USA 711 E. Boldt Way 54911

${ }^{13}$ Société d'Histoire Naturelle Alcide-d'Orbigny, 63170 Aubière, France

${ }^{14}$ Instituto de Ciencias Biológicas, Escuela Politécnicamenk Nacional, CP 17-01-2759 Quito, Ecuador 
${ }^{15}$ Center for Macroecology, Evolution, and Climate, Natural History Museum of Denmark, University of Copenhagen, universitetsparken 15, building 2, $2^{\text {nd }}$ floor, DK-2100 penhagen, Denmark

${ }^{16}$ Biology Centre of the Czech Academy of Sciences, Institute of Entomology, and Faculty of Science, University of South Bohemia, Branišovská 31, České Budějovice 370 05, Czech Republic

${ }^{17}$ Appalachian Lab, University of Maryland Center for Environmental Science, Frostburg, MD, USA

${ }^{18}$ Department of Environmental Science, University of Girona, Montilivi Campus, 17003 Girona, Spain

${ }^{19}$ School of Biological Sciences, The University of Hong Kong, Hong Kong SAR

${ }^{20}$ Department of Environment and Agriculture, Curtin University, Perth, WA 6102, Australia

${ }^{21}$ CSIRO, Tropical Ecosystems Research Centre, PMB 44, Winnellie, NT, 0822, Australia

${ }^{22}$ National Laboratory for Ecological Analysis and Synthesis (LANASE), ENES, UNAM, 58190 Morelia, Michoacan, Mexico

${ }^{23}$ IPE - Instituto de Pesquisas Ecológicas, Nazaré Paulista, SP, Brasil 12960-000

${ }^{24}$ New Guinea Binatang Research Center, P.O. Box 604, Madang, Papua New Guinea.

${ }^{25}$ College of Science and Engineering, James Cook University, Cairns, Queensland, Australia 4870

${ }^{26}$ Department of Experimental Diabetology (DIAB), German Institute of Human Nutrition Potsdam-Rehbruecke (DIfE), Arthur-Scheunert-Allee 114-116, 14558 Nuthetal, Germany 27 iodiversity Monitoring \& Assessment, Royal Belgian Institute of Natural Sciences, 1000 Brussels, Belgium 
${ }^{28}$ University of Florida Entomology \& Nematology Department, Gainesville, FL, USA

${ }^{29}$ School of Biological Sciences, University of WA, Perth, WA 6009, Australia

${ }^{30}$ Department of Biology, Lake Forest College, Lake Forest, IL 60045, USA.

${ }^{31}$ antbase.net, Germany

${ }^{32}$ School of Life Sciences, University of KwaZulu-Natal, Pietermaritzburg, South Africa

${ }^{33}$ ITZ, Ecology and Evolution, TiHo Hannover, Hannover, Germany

${ }^{34}$ Department of Biogeography, University of Bayreuth, Universitätsstrasse 30, 95447

Bayreuth

${ }^{35}$ Environmental Studies Department, University of California, Santa Cruz, USA

${ }^{36}$ Science and Technology for Amazonian Resources Graduate Program, Institute of Exact

Sciences and Technology (ICET), R. Nossa Senhora do Rosário, 3863, Tiradentes. CEP:

69103-128, Itacoatiara, AM, Brazil

${ }^{37}$ Biodiversity Coordination, National Institute for Amazonian Research (INPA), Av. André Araújo, 2936, Petrópolis. CEP: 69067-375-Manaus, AM, Brazil

${ }^{38}$ Division of Tropical Ecology and Animal Biodiversity, Department of Botany and Biodiversity Research, University of Vienna, Rennweg 14, A-1030 Vienna

${ }^{39}$ Instituto de Biologia, Universidade Federal de Uberlândia, Av. Pará 1720, 38405-320

Uberlândia, MG, Brazil

${ }^{40}$ Univ Autònoma Barcelona, Cerdanyola del Vallès, Catalunya, Spain 
Corresponding author:

Xavier Arnan

CREAF, Campus UAB, 08193 Cerdanyola del Vallès, Spain

Telephone number: +34935814221

Fax number: +34935814151

Email address: xavi.arnan@gmail.com

\section{ABSTRACT}

The relationship between levels of dominance and species richness is highly contentious, especially in ant communities. The dominance-impoverishment rule states that high levels of dominance only occur in species-poor communities, but there appear to be many cases of high levels of dominance in highly diverse communities. The extent to which dominant species limit local richness through competitive exclusion remains unclear, but such exclusion appears more apparent for non-native rather than native dominant species. Here we perform the first global analysis of the relationship between behavioral dominance and species richness. We used data from 1293 local assemblages of ground-dwelling ants distributed across five continents to document the generality of the dominanceimpoverishment rule, and to identify the biotic and abiotic conditions under which it does and does not apply. We found that the behavioral dominance - diversity relationship varies greatly, and depends on whether dominant species are native or non-native, whether dominance is considered as occurrence or relative abundance, and on variation in mean annual temperature. There were declines in diversity with increasing dominance in invaded communities, but diversity increased with increasing dominance in native communities. These patterns occur along the global temperature gradient. However, positive and negative relationships are strongest in the hottest sites. We also found that climate regulates the degree 
of behavioral dominance, but differently from how it shapes species richness. Our findings imply that, despite strong competitive interactions among ants, competitive exclusion is not a major driver of local richness in native ant communities. Although the dominanceimpoverishment rule applies to invaded communities, we propose an alternative dominancediversification rule for native communities.

Keywords: ants, behavioral dominance, coexistence, dominance-impoverishment rule, global scale, invasive species, precipitation, species richness, temperature

\section{INTRODUCTION}

Understanding the factors that drive variation in local species richness at different spatial and temporal scales remains a fundamental challenge to community ecology (Ricklefs, 1987; Chesson, 2000; Kneitel \& Chase, 2004). Regional species pools are determined by evolutionary and historical factors, while environmental filtering and dispersal barriers set the limit on the species that might potentially occur in a local community (Cornell \& Harrison,

14). The final realized diversity of communities then depends on local biotic interactions such as competition (Silvertown et al., 2006). The relative importance of competition is thought to vary predictably with environmental stress and disturbance, both of which constrain the capacity of dominant species to achieve levels of resource monopolization that lead to the exclusion of other species (Connell, 1978; Grime, 1979).

The stress-disturbance-competition framework was originally developed for communities of plants (Grime, 1979) and other sessile organisms (Connell, 1978), but has also been applied to macro-scale analyses of the dynamics of ant communities (Andersen, 1995; 1997a). Like 
plants, ants are principally central-place foragers whose foraging modules ramify in the environment to an extent that allows resource monopolization, leading to higher levels of competition than is the case for many other faunal groups (Andersen, 1991). Behavioral dominant species are aggressive species that are capable of exerting a strong influence on other species (Cerdá et al., 2013). The primary factors limiting ant productivity and the abundance of behaviorally dominant species are considered to be temperature (including a requirement of direct solar radiation), a structurally simple foraging environment, and the supply of liquid carbohydrates, particularly honeydew (Andersen 2010; Dunn et al., 2009). ese factors combine in two highly contrasting environments, the canopies of lowland tropical rainforest, and on the ground in warm open habitats where honeydew is readily available (Andersen, 2000; 2003; 2010). The abundance of behaviourally dominant species is likewise highest in these environments (Andersen, 1995; 1997a; Davidson et al., 2003; Blüthgen \& Fiedler, 2004).

Despite competition being regarded as the 'hallmark of ant ecology' (Hölldobler \& Wilson, 1990), its role as a driver of community assembly and species richness remains somewhat contentious (Cerdá et al., 2013; Stuble et al., 2017). Hölldobler \& Wilson (1990) proposed the 'dominance-impoverishment rule' to describe a negative relationship between local ant species richness and the abundance of behaviorally dominant species: "the fewer the ant species in a local community, the more likely the community is to be dominated behaviorally by one or a few species with large, aggressive colonies that maintain absolute territories". This tenet was based on studies across a wide variety of environments, ranging from temperate and boreal forests of Europe (e.g., Vepsäläinen \& Pisarski, 1982) to the canopies of tropical Africa and Australia (e.g., Room, 1971; Hölldobler, 1983). Hölldobler \& Wilson (1990) argued that the high abundance of behaviorally dominant ants was due to the low 
diversity of the sites in which they were found, rather than the cause of the low diversity. Both mechanisms, however, are possible. Here we use the term 'dominance-impoverishment rule' to describe the pattern generally, regardless of its mechanism.

There have been many studies showing that behaviourally dominant ants exclude other species from near their nests (Savolainen et al., 1989; Parr, 2008; Cerdá et al., 2013) and from high-value food resources (Andersen, 1992; Parr et al., 2005). The presence of behaviourally dominant non-native (i.e., invasive) species often reduces local species richness through competitive exclusion (Hoffmann et al., 1999; Holway et al., 2002; Lach \& Hooper-Bùi, 2010). However, there is only limited evidence that competitive exclusion by native species can be an important driver of patterns of local species richness (Andersen, 1992; Parr, 2008), and this does not typically appear to be the case (Albrecht \& Gotelli, 2001;

bb \& Hochuli, 2004; Baccaro et al., 2012; Stuble et al., 2017) and may be conditional on environmental disturbance (Gibb, 2011). Many examples of high levels of competitive dominance co-occur with high ant diversity, especially in Australia (Andersen, 2008; 2016; Arnan et al., 2011).

We perform the first global analysis of the relationship between behavioral dominance and species richness in any faunal group, using data from 1,293 local ant assemblages distributed across five continents. In local communities, competitive exclusion is often expressed as a humped relationship between the abundance of dominant species and local species richness, conforming to general models of the control of local diversity in relation to resource availability (Grime, 1973; Cardinale et al. ,2009), productivity (Tilman, 1982) and disturbance (Connell, 1978; MacKey \& Currie, 2001). Few species occur under hostile 
environmental conditions, where the abundance of behaviorally dominant species will likewise be very low. Both species richness and the abundance of dominant species can be expected to increase as environmental favorability improves, forming the ascending side of the humped diversity curve (Andersen, 1992; Parr et al., 2005). For example, local species richness increases with temperature up to a point (Dunn et al., 2009; Jenkins et al., 2011), and this also appears to be the case for the abundance of dominant ants (Andersen, 1995; 1997a). If competitive exclusion occurs, an inflection point will be reached where a continued increase in the abundance of dominant species is associated with declining species richness, creating the descending side of the humped diversity curve (Andersen, 1992; Parr et al., 2005). In such a case, an extremely high abundance of dominant species would be associated with very low species richness, conforming with the dominance-impoverishment rule.

However, humped diversity models in relation to environmental stress and disturbance apply to assemblages of species from clearly circumscribed environments (Chase \& Leibold, 2002), and such patterns cannot be expected to emerge from broader scale analyses, where local processes are often overwhelmed by regional factors such as variation in climate (Andersen, 1997b). A more robust global test of the relationship between dominant species and species richness is to compare species richness with and without dominant species under matched climates.

The objective of our study is to examine the global relationship between behavioral dominance and diversity in ant communities, in the context of testing the generality of the dominance-impoverishment rule and its environmental drivers. Our specific aims are to: (1) compare species richness with and without the occurrence of dominant species; (2) document 
the global relationship between species richness and the abundance of dominant species; and (3) analyze the interactions between climate, the abundance and identity (native or nonnative) of dominant species and ant richness. We predict that whereas high levels of behavioural dominance are associated with low diversity in invaded communities, this is not the case when dominant species are native. We therefore predict that the dominanceimpoverishment rule applies to communities dominated by non-native species, but not by native species.

\section{MATERIALS AND METHODS}

\section{Ant assemblage database}

We assembled species composition data from 1,293 local ground-dwelling ant communities around the world (Fig. 1). The database includes primary data collected during the authors' own field work and data derived from an exhaustive search of the scientific literature. The data are compiled in the Global Ants Database (GLAD, http://globalants.org/), a collaboration among ant ecologists worldwide bringing together data on the abundance and traits of ants in local assemblages worldwide (Dunn et al., 2009; Gibb et al., 2017; Parr et al., 2017). Ant assemblages included in this study met the following criteria: (1) the groundforaging ant assemblage was sampled using pitfall trapping. We wanted to ensure that sampling was standardized, and pitfall traps were the most commonly used sampling technique in GLAD. If Winkler, Berlese funnel or bait sampling were conducted in addition to pitfall trapping, then such supplementary data were also used; (2) sampling was not trophically or taxonomically limited (for example, the study was not focused only on seedharvesting ants); (3) study sites had not undergone habitat transformation due to intensive land use, such as cropping or clear-cut forestry (we included moderately disturbed sites, such 
as those affected by fire or grazing; such disturbance did not affect the presence of invasive ant species in our data set: Generalized linear mixed model, $\chi_{1}^{2}=0.96, p=0.326$ ); and (4) we had information on factors such as sampling intensity and habitat type that might confound the behavioral dominance - diversity relationship, and which were included as covariates in statistical models (see below). Assemblage data came from all continents where ants occur: Oceania (41.0\% of sites), North America (18.6\%), Europe (16.6\%), Africa (11.8\%), South America (8.2\%), and Asia (3.8\%). GLAD includes data sets for regions that are not wellrepresented in our analyses, but unfortunately these did not meet our selection criteria, especially relating to the use of pitfall traps.

\section{Defining behavioral dominance and invasive (non-native) species}

We focused on the relationship between diversity and behavioral dominance, rather than simply numerical dominance, because this is specified in the dominance-impoverishment rule. At any rate, in those sites where behaviorally dominant species occurred, the abundance of behaviorally dominant species was highly correlated to the abundance of the most abundant species (Spearman $\mathrm{r}=0.96, \mathrm{p}<0.0001, \mathrm{n}=645)$, i.e. behavioral and numerical dominance was highly correlated. We considered a species to be behaviorally dominant based on both aggressive behavior and effects on other species by excluding them from near their nests and from high-value food resources (Vepsäläinen \& Pisarski, 1982; Savolainen et al., 1989; Andersen, 1992; Cerdá et al., 2013). Behaviorally dominant species are thus defined as highly aggressive species that usually predominate numerically, occupy large territories, and have mutually exclusive distribution patterns at local scales. Given the large number of studies use, data are not available to demonstrate impact by dominant species in each of our study communities, and so we had to rely on a priori classifications of taxa based on the 
literature and our combined expert knowledge. The following taxa were thus classified as behaviorally dominant (Appendix S1): Anonychomyrma, Anoplolepis, Azteca, Dorymyrmex (except insana group), Formica (only exsecta and rufa groups), Froggattella, Iridomyrmex, Linepithema, Liometopum, Oecophylla, Papyrius, Pheidole (only megacephala and fallax groups), Philidris, Solenopsis (sub-genus Solenopsis, i.e. "fire ants"), Tapinoma (nigerrimum group), and Wasmannia auropunctata. There is considerable empirical evidence that species in these taxa are behaviorally dominant and influence the structure and dynamics of local ant communities (e.g., Andersen, 1995; 1997a; Savolainen et al., 1989; Lach \& Hooper-Bùi, 2010; Arnan et al., 2011; Cerdá et al., 2013; Bertelsmeier et al., 2015a). Some species from other genera (e.g., Crematogaster) might also be good candidates, but the distribution of behavioural dominance among constituent species groups is poorly known, and so they have not been included. Army-ants (subfamily Dorylinae) were also not included. These species are behavioural dominant species, but their effects on other ant species are temporally limited given their nomadic life style.

Our pool of behaviorally dominant species included five invasive species occurring in our communities outside their native ranges: the yellow crazy ant (Anoplolepis gracilipes), the Argentine ant (Linepithema humile), the big-headed ant (Pheidole megacephala), fire ants (Solenopsis spp., subgenus Solenopsis) and the electric ant (Wasmannia auropunctata) (Lach \& Hooper-Bùi, 2010; Bertelsmeier et al., 2015a; 2015b; 2016). These species are considered the five top invasive ants (Bertelsmeier et al., 2016) and are on the list of the "100 of the world's worst invasive alien species" (Lowe et al., 2000). 


\section{Climatic characterization of sites}

We selected two climatic variables that are consistently related to variation in ant communities globally (e.g., Dunn et al., 2009; Jenkins et al., 2011; Arnan et al., 2014; Gibb et al., 2015): mean annual temperature (hereafter, temperature) and annual precipitation (hereafter, precipitation). We acknowledge that other aspects of climate such as seasonality can have an important influence on ant communities, but there is no evidence that they are key drivers of ant diversity at a global scale. For each locality, temperature and precipitation information was obtained for the period 1950 - 2000 from the WORLDCLIM database (http://www.worldclim.org/bioclim) using rasters with the highest available resolution (30 arc-s, approx. $1 \mathrm{x} 1 \mathrm{~km}$ ). Such a resolution provides climatic data that are directly applicable to the scale of sampling in our study communities (approximately $1 \mathrm{ha}$ ).

\section{Data analyses}

All analyses were performed in R v.3.2.4 statistical environment (R Core Team, 2016). We initially determined that temperature and precipitation were significantly but not highly correlated (Spearman $r=0.27, p<0.0001$ ), so both variables were retained for analyses.

We considered behavioral dominance at two levels: the (1) occurrence (presence-absence) and (2) abundance of dominant species in a site. Occurrence data were considered for all 1,293 sites, whereas abundance data were considered only for those 645 sites where behaviorally dominant species occurred and where abundance data were available, in order to remove the effects of a high proportion of zeros. Abundance of behaviorally dominant species was computed as a proportion of total individuals sampled for all species combined. 
We used two general linear mixed models (GLMMs) to test how behavioral dominance and climate relate to ant species richness. The first model used occurrence of dominant species (sites with vs sites without dominants), temperature and precipitation as explanatory variables with ln-transformed species richness as the response variable ('Global occurrence model', Table 1). The second model used abundance of dominant species, temperature and precipitation as explanatory variables with ln-transformed species richness as the response variables ('Global abundance model', Table 1). The abundance model also included the quadratic term of abundance, in case the relationship was unimodal (Andersen, 1992; Parr et al., 2005; Parr, 2008). To compare dominance-diversity relationships under native vs nonnative dominant species and along climate gradients, we first classified sites into three categories: "sites without dominants", "sites with native dominants" and "sites with nonnative dominants" (our data set included no sites with both native and non-native dominants). We then tested the relationship between the interaction of dominant type (no dominants, native dominants, non-native dominants) and the climatic variables (temperature and precipitation) on species richness (ln-transformed) by using a GLMM ('Dominants type $\mathrm{x}$ climate model', Table 1). We also analyzed the relationship between the abundance of native and non-native dominant ants and species richness (ln-transformed) in separate GLMM models ('Native dominants x climate model'; and 'Non-native dominants x climate model'; Table 1). Both models included the interaction of the abundance of dominant ants and its quadratic term with the climatic variables (temperature and precipitation) as explanatory variables.

Finally, we analyzed how climate variables shape the relative abundance of native and nonnative dominant species in two separate models where only the sites where dominants occurred and with available abundance data were used ('Climate model of native dominants' 
and 'Climate model of non-native dominants', Table 1). In both models, the explanatory variables were temperature, precipitation and their interaction, and the abundance of native and non-native dominants species (logit transformed) were the response variables, respectively. All models included a set of covariates as fixed variables that were used to control for variation in sampling effort (number of trap days and transect length), region (continent and hemisphere) and habitat structural type (forest or open habitat).

We used mixed-effects models because sites were spatially clustered. Thus, clusters of sites separated by no more than $100 \mathrm{~km}$ from each other were represented by a single random effect to control for potential autocorrelation between localized sites (see Gibb et al., 2015) while allowing the direct comparison between sites from nearby locations. The mixed-effect models (GLMMs) were fitted with the lme function in lme4 package in R. Akaike's Information Criterion with a correction for finite sample sizes (AICc) was used to select the best-supported models (Burnham \& Anderson, 2002). In each analysis, models were constructed using all combinations of explanatory variables. The best-supported models for each analysis were selected based on the AICc weights, which reveal the relative likelihood of a given model—based on the data and the fit—scaled to one; thus, models with a delta (AICc difference) $<2$ were selected (Burnham \& Anderson, 2002). We selected as relevant variables those that were included in the best-supported models. The model selection procedure was conducted using the dredge function in the MuMIn package in R. Both rginal and conditional $\mathrm{R}^{2}$ values of the best-supported models (which give the variation explained by fixed as well as fixed + random effects, respectively) were reported (Nakagawa \& Schielzeth, 2013). 


\section{RESULTS}

Mean species richness was significantly higher at sites with than without dominant species

(Table 1, 'Global occurrence model', Fig. 2; Appendix S2 for more details on outputs from model selection procedure), a pattern that was consistent between temperate latitudes and subtropical and tropical latitudes. Species richness increased linearly with mean annual perature $\left(\mathrm{R}^{2}\right.$ marginal/conditional $\left.=0.23 / 0.65\right)$, but not with annual precipitation (Table 1 , 'Global occurrence model'). These relationships varied according to whether dominant species occurred at a site, and whether the dominant species were native or non-native, such that species richness tended to be lowest at sites with non-native dominant species, and highest at sites with native dominant species (Table 1, 'Dominants type x climate model', Fig. 3a). Mean species richness was $31.9 \%$ higher at sites with dominant species than those without $\mathrm{y}$ when the dominant species were native, but was $4.6 \%$ lower when the dominant species were non-native. The difference between sites dominated by non-native species and sites without dominant species varied markedly with temperature: there was no difference in species richness at low temperatures (temperature $<15^{\circ} \mathrm{C}$ ), but as temperature increased, the difference between the two increased such that by $27^{\circ} \mathrm{C}$, there were $27.5 \%$ more species in sites without dominants than in sites with non-native dominants (Fig. 3a). In contrast, species richness at sites dominated by native species tended to be higher than at sites without dominant species, although the difference increased with increasing temperature (Fig. 3a). Moreover, whereas native dominant species occurred across the full temperature gradient, non-native dominant species were absent from the coldest sites (temperature $<7^{\circ} \mathrm{C}$; Fig. $3 \mathrm{~A}$ ). Notably, all sites in the very hottest environments (temperature $>27^{\circ} \mathrm{C}$ ) had dominant species, and they were mostly native rather than non-native (Fig. 3a). 
At sites where dominant species occurred and where abundance data were available, there was a unimodal relationship between species richness and the abundance of behaviorally dominant species (Table 1, 'Global abundance model'), with a very shallow ascending side of

curve but steeper descent (Fig. $3 \mathrm{~b}, \mathrm{R}_{\text {marginal/conditional }}^{2}=0.20 / 0.72$ ). Species richness was not only lower when non-native species were present relative to when they were absent, but it declined at a faster rate as their relative abundance increased (Table 1, 'Native dominants $\mathrm{x}$ climate' and 'Non-native dominants x climate' models, Fig. 3b). In both cases there was no interaction between relative abundance of dominant species and either temperature or precipitation (Table 1, 'Native dominants x climate' and 'Non-native dominants x climate' models). The relative abundance of non-native dominant species was not related to either temperature or precipitation, whereas that of native dominant species was related to both (Table 1, 'Climate model of non-native dominants' and 'Climate model of native dominants'). There was a very shallow U-shaped relationship between the relative abundance of native dominants and temperature (Fig. 4a), with the relative abundance of dominants tending to be highest at the lowest and highest temperatures. The relative abundance of native dominant ants was negatively related to precipitation (Fig. 4b).

\section{DISCUSSION}

In nearly 1,300 local ant assemblages distributed across five continents, we found that where dominant species occurred and abundance data were available, the relationship between dominance and richness is humped-shaped. Such a relationship parallels models of the control of diversity in communities of plants and sessile intertidal organisms along gradients of resource availability (Grime, 1973), productivity (Tilman, 1982), or disturbance (Connell, 1978). A premise in these models is that diversity initially increases with environmental favorability but then decreases as conditions allow highly competitive species to become so 
dominant that they exclude other species. Such a unimodal relationship has been documented in ants sampled at very localized food resources in a variety of local communities (Andersen, 1992; Parr et al., 2005; Campbell et al., 2015). However, there is only limited evidence that competitive exclusion from local food resources scales up to exclusion at the site level (e.g., bb \& Hochuli, 2004; Baccaro et al., 2012; Parr, 2008).

What causes the descending side of the dominance-diversity curve? It cannot necessarily be attributed to competitive exclusion because the humped model applies specifically to local communities, and at larger scales there are confounding effects of climatic drivers of ant diversity. For example, if communities corresponding to very high levels of behavioural dominance associated with very low levels of species richness are from low-diversity systems (e.g. Formica-dominated communities from boreal forests), then this is not evidence of competitive exclusion in highly diverse systems. Indeed, our analysis shows many examples of very high diversity occurring with very high levels of behavioural dominance, and when native dominant species were present, species richness was actually higher than at sites without dominant species. The dominance-impoverishment 'rule' is clearly not a general one.

The shape of the dominance-diversity relationship depended on whether the dominant species were native or non-native. In contrast to the situation with native dominant species, when the dominant species were non-native, species richness was $4.6 \%$ lower at sites with dominant species than those without. We thus found a positive relationship between the occurrence of dominant ants and species richness when the dominant species were native, but a negative relationship when they were non-native. There were also different relationships between species richness and the abundance of dominant species depending on whether the dominant 
species were native or non-native, with the negative slope being much steeper in the latter. Ant richness increased with temperature regardless of whether dominant species were present, or whether dominant species were native or non-native. However, its interaction with behavioural dominance varied markedly with temperature. At lower temperature, sites with non-native dominant species had the same richness as those without dominant species, but had progressively lower richness with increasing temperature. Sites with native dominant species had higher richness than those without dominant species across the full temperature range, but slightly more so at higher temperature. Moreover, native dominant species occurred across the full temperature range, but non-native dominant species did not occur at either the coldest or hottest sites. The relative abundance of native dominant ants was lowest at moderate temperature, being greater at lower and higher temperature, and was highest at driest sites, whereas the relative abundance of non-native species was not related to climate.

The extent to which the dominance-diversity relationships that we have reported are causal is unclear. The association between the occurrence of non-native dominant species and lower species richness can at least partly be explained by competitive exclusion, given that the elimination of native species by invasive invaders has been well demonstrated (Holway et al., 2002; Lach \& Hooper-Bùi 2010; Stuble et al., 2013). This is consistent with our finding that the association of non-native dominant ants with lower diversity increased with temperature, given that the effects of competition typically increase with increasing productivity (Grime, 1979; Andersen, 1995; 1997a; Rees, 2013), and productivity in ants is strongly related to temperature (Andersen, 1995). 
There are alternative explanations for the association of native dominant species with higher species richness. The most parsimonious explanation is that species richness and the abundance of native dominant species show parallel responses to increasing climatic favourability (Andersen, 1995). We found a positive relationship between temperature and ant species richness, and native dominant species occupy sites with higher temperature compared to sites without dominant species. However, we found that species richness tends to be higher in sites with dominant species than those without dominant species, regardless of temperature. Moreover, if habitat favorability alone is at work, we would expect parallel responses of species richness and the abundance of native dominants to mean annual temperature, but this was not the case (species richness increased linearly along the temperature gradient, but the abundance of dominant species followed a U-shaped relationship with temperature). The best-supported climate model of native dominants kept most covariates, suggesting that native dominants may be responding differently depending on the continent, hemisphere and habitat type.

An alternative explanation is that dominant species actually promote species richness. Such facilitation might be through increased heterogeneity and resource availability, as suggested by Gibb (2011) for northern Europe in a study at the regional scale in boreal forests. Although Gibb (2001) found facilitation by dominant ants in the most disturbed (least productive) sites, we found that the presence of native dominant species had the greatest impact on species richness at warm (i.e. more productive) sites. Our results are consistent with the finding that facilitation occurs primarily at the most productive sites (Golberg et al., 1999). An alternative mechanism for facilitation of species richness by dominant species is that they moderate the suppressive effect of subdominant species on subordinate species (Arnan et al., 2011). Further experimental work (see below) is required to clarify the causal 
mechanism(s) behind the positive relationship between species richness and the abundance of dominant species.

Why might non-native dominant species have a negative effect on local species richness when native dominant species do not? One explanation is a lack of co-evolution between invasive and native species, such that native species lack the particular compensatory mechanisms (e.g. niche partitioning, thermal tolerance-behavioral dominance trade-offs) that would allow coexistence (Cerdá et al., 2013). In non-invaded areas, dominant and nondominant species have evolved together and different compensatory mechanisms that allow coexistence have arisen; facilitation processes might even promote stable coexistence among species (Hart \& Marshall, 2013). It is also worth mentioning that invasion and species richness suppression by invasive ant species has not been recorded for high-diversity systems with high levels of behavioral dominance of native species, that is, invasion and exclusion might only occur in communities that are 'naïve' to dominance. Another explanation relates to differences in social structure between native and non-native dominants: unlike many native species, invasive populations are often unicolonial (a population of ants inhabiting a single large polydomous colony), and so there is little or no aggression between workers from different nests (Passera, 1994; Holway et al., 2002; Robinson, 2014). Notably, Linepithema humile is entirely unicolonial in its introduced range, but often is not in its native range (Giraud et al., 2002). Such a difference in social structure might have a major role in shifting competition for resources from intraspecific (in multicolonial species of native dominant species) to interspecific (in unicolonial species of invasive dominant species), and thus potentially exerting a greater effect on local species richness. 
The mechanisms underlying the dominance-diversity relationships we have reported are best tested through experimental manipulation of dominant ants (Gibb \& Johansson, 2011). However, experimental removals or additions of dominant species (either native or nonnative) have shown conflicting results, variably showing positive (Gibb, 2011), negative (King \& Tschinkel, 2008; Blinova, 2011; Gibb, 2011) or neutral (Andersen \& Patel, 1994; bb \& Hochuli, 2004; King \& Tschinkel, 2006; 2013; Gibb \& Johansson, 2011) effects on species richness. This suggests the effects of dominant species on species richness might depend on biotic (e.g., whether dominant species are native or non-native) and abiotic conditions (e.g., climate or habitat structure), as well as the interaction between them.

If our results really are caused by interactions between dominant ants and the rest of the community, then this implies that biotic interactions (competition and possibly also facilitation) can be important drivers of diversity patterns at macro-ecological as well as local scales (Stubbs \& Wilson, 2004; Slingsby \& Verboom, 2006). We call for revisiting macroecological studies that present environmental constraints as drivers of spatial patterns of diversity at large spatial scales when these studies were unable to distinguish environmental filtering from the outcome of biotic interactions. For instance, the effects of environmental favorability on species richness might be severely under- or overestimated in areas where non-native or native dominant species occur, respectively. Our results also raise serious concerns relating to some key drivers of global change. Economic globalization is triggering an exponential increase in the number of introductions of exotic species (Butchart et al., 2010; Essl et al., 2011), and climate change is predicted to promote a proliferation of several non-native dominant ant species (Bertelsmeier et al., 2015b). Our findings suggest that re uctions in ant diversity by dominant species will be greatest under a combination of 
highest temperatures with highest occurrence of non-native ant species, and the frequency of this scenario is likely to increase under global change.

In conclusion, we have shown that dominance-diversity relationships in ant communities vary markedly depending on whether dominant species are native or non-native. In particular, the association of high levels of behavioural dominance with low species richness that is often observed in invaded communities does not typically occur in native communities. Indeed, species richness in communities with native dominant species is consistently higher than in communities lacking dominant species. The dominance-impoverishment rule appears to be restricted to invaded communities, and we propose a 'dominance-diversification rule' for native communities.

Such dominance-diversification appears to be peculiar to ants. Although ants have many parallels with plants in that both are central-place foragers with complex foraging modules, in plant communities both native and non-native dominant species exert negative influences on species diversity (Grime, 1973, Pyšek et al., 2012). As central place foragers, dominant ants cannot persistently monopolize key resources within their foraging territories in the comprehensive way that dominant plants can. Canopy trees, for instance, can comprehensively monopolize key plant resources such as light, providing no opportunity for the sort of temporal or fine-scale spatial niche differentiation, variable outcomes of competition, or forager priority effects that facilitate species co-existence in ant communities (Andersen, 2008). However, the dominance-diversification rule might apply to other mobile animal groups that, like ants, are organized in complex behavioral dominance hierarchies 
(i.e., hummingbirds, fishes, lizards) (Werner, 1976, Des Granges, 1979), and further research is needed to test the applicability of this rule among other faunal taxa.

\section{ACKNOWLEDGEMENTS}

X.A. was supported by a Ramón y Cajal research contract by the Spanish Ministry of Economy and Competitiveness (RYC-2015-18448) and by the Conselho Nacional de Desenvolvimento Científico e Tecnológico of Brazil (CNPq PDS-167533/2013-4 and PDS165623/2015-2). P.K., J.M. and M.J. were supported by the Czech Science Foundation (14098G), European Research Council (GA669609) and Czech Academy of Sciences (FNRS17-04). T.M.F. was supported by the Czech Science Foundation (16-09427S). M.P. was supported by the German Academic Exchange Service (DAAD, D 10 00351). Financial support from the German Academic Exchange Service (DAAD) for the PhD study of O.P. in Germany is gratefully acknowledged. J.L.P.S was supported by the Fundação de Amparo à Pesquisas do Estado do Amazonas (FAPEAM FIXAM/AM 062.01325/ 2014).

\section{REFERENCES}

Albrecht, M. \& Gotelli, N.J. (2001) Spatial and temporal niche partitioning in grassland ants. Oecologia, 126, 134-141.

Andersen, A.N. (1991) Parallels between ants and plants: implications for community ecology. In C.R. Huxley \& D.F. Cutler (Eds.), Ant - Plant interactions (pp. 539-538). Oxford, UK: Oxford University Press. 
Andersen, A.N. (1992) Regulation of "momentary" diversity by dominant species in exceptionally rich ant communities of the Australian seasonal tropics. American Naturalist, $140,401-420$.

Andersen, A.N. (1995) A classification of Australian ant communities, based on functional groups which parallel plant life-forms in relation to stress and disturbance. Journal of Biogeography, 22, 15-29.

Andersen, A.N. (1997a) Functional groups and patterns of organization in North American ant communities: a comparison with Australia. Journal of Biogeography, 24, 433-460.

Andersen, A.N. (1997b) Using ants as bioindicators: multi-scale issues in ant community ecology. Conservation Ecology, 1, 8.

Andersen, A.N. (2000) A global ecology of rain forest ants: functional groups in relation to stress and disturbance. In D. Agosti, J.D. Majer, L. Alonso \& T. Shultz (Eds.), Ants: Standard Methods for Measuring and Monitoring Biodiversity (pp. 25-34). Washington D.C., USA: Smithsonian Institution Press.

Andersen, A.N. (2008) Not enough niches: non-equilibrial processes promoting species coexistence in diverse ant communities. Austral Ecology, 33, 211-20.

Andersen, A.N. (2010) Functional groups in ant community ecology. In L. Lach, C.L. Parr \& K. Abbott (Eds.), Ant Ecology (pp. 142-144). Oxford, UK: Oxford University Press.

Andersen, A.N. \& Patel, A.D. (1994) Meat ants as dominant members of Australian ant communities: an experimental test of their influence on the foraging success and forager abundance of other species. Oecologia, 98, 15-24.

Arnan, X., Cerdá, X. \& Retana, J. (2014) Ant functional responses along environmental gradients. Journal of Animal Ecology, 83, 1398-1408. 
Arnan, X., Gaucherel, C. \& Andersen, A.N. (2011) Dominance and species co-occurrence in highly diverse ant communities: a test of the interstitial hypothesis and discovery of a competition cascade. Oecologia, 166, 783-794.

Baccaro, F.B., de Souza, J.L.P., Franklin, E., Landeiro, V.L. \& Magnusson, W.E. (2012) Limited effects of dominant ants on assemblage species richness in three Amazon forests. Ecological Entomology, 37, 1-12.

Bertelsmeier, C., Avril, A., Blight, O., Confais, A., Diez, L., Jourdan, H. et al. (2015a) Different behavioural strategies among seven highly invasive ant species. Biological Invasions, 17, 2491.

Bertelsmeier, C., Luque, G.M., Hoffmann, B.D. \& Courchamp, F. (2015b) Worldwide ant invasions under climate change. Biodiversity and Conservation, 24, 117-128.

Bertelsmeier, C., Blight, O. \& Courchamp, F. (2016) Invasions of ants (hymenoptera: formicidae) in light of global climate change. Myrmecological News, 22, 25-43.

Blinova, S.V. (2011) Changes in the ant assemblage of pine-birch forest upon removal of the nests of dominant species. Russian Journal of Ecology, 42, 525-528.

Blüthgen, N. \& Fiedler, K. (2004) Competition for composition: Lessons from nectar-feeding ant communities. Ecology, 85, 1479-1485.

Burnham, K.P. \& Anderson, D.R. (2002) Model Selection and Multimodel Inference: A Practical Information-Theoretic Approach. New York, NY: Springer-Verlag.

Butchart, S.H.M., Walpole, M., Collen, B., van Strien, A., Scharlemann, J.P.W., Rosamunde, E.A., et al. (2010). Global biodiversity: indicators of recent declines. Science, 328, $1164-$ 1168. 
Campbell, H., Fellowes, M.D.E. \& Cook, J.M. (2015) Species diversity and dominancerichness relationships for ground and arboreal ant (Hymenoptera: Formicidae) assemblages in Namibian desert, saltpan, and savannah. Myrmecological News, 21, 37-47.

Cardinale, B.J., Hillebrand, H., Harpole, W.S., Gross, K. \& Ptacnik, R. (2009) Separating the influence of resource 'availability' from resource 'imbalance' on productivity-diversity relationships. Ecology Letters, 12, 475-487.

Cerdá, X., Arnan, X. \& Retana, J. (2013) Is competition a significant hallmark of ant (Hymenoptera: Formicidae) ecology? Myrmecological News, 18, 131-147.

Chasse, J.M. \& Leibold, M.A. (2002) Spatial scale dictates the productivity-biodiversity relationship. Nature, 416, 427-430.

Chesson, P. (2000) Mechanisms of maintenance of species diversity. Annual Review of Ecology, Evolution, and Systematics, 31, 343-66.

Connell, J.H. (1978) Diversity in tropical rain forests and coral reefs. Science, 199, 13021310.

Cornwell, W.K., Schwilk, D.W. \& Ackerly, D.D. (2006) A trait-based test for habitat filtering: convex hull volume. Ecology, 87, 1465-1471.

Davidson, D.W., Cook, S.C., Snelling, R.R. \& Chua T.H. (2003) Explaining the abundance of ants in lowland tropical rainforest canopies. Science, 300, 969-973.

Des Granges, J.L. (1979) Organization of a tropical nectar feeding bird guild in a variable environment. Living Bird, 17, 199-236.

Dunn, R.R., Agosti, D., Andersen, A.N., Arnan, X., Bruhl, C.A., Cerdá, X. et al. (2009) Climatic drivers of hemispheric asymmetry in global patterns of ant species richness. Ecology Letters, 12, 324-333. 
Essl, F., Dullinger, S., Rabitsch, W., Hulme, P.E., Hülber, K., Jarosik, V. et al. (2011)

Socioeconomic legacy yelds an invasion debt. Proceedings of the National Academy of Sciences of the United States of America, 108, 203-207.

Gibb, H. (2011) Experimental evidence for mediation of competition by habitat succession. Ecology, 92, 1871-1878.

Gibb, H., Dunn, R.R., Sanders, N.J., Grossman, B.F., Photakis, M., Abril, S., et al. (2017) A global database of ant species abundances. Ecology, 98, 883-884.

Gibb, H. \& Hochuli, D.F. (2004) Removal experiment reveals limited effects of a behaviorally dominant species on ant assemblages. Ecology, 85, 648-657.

Gibb, H. \& Johansson, T. (2011) Field tests of interspecific competition in ant assemblages: revisiting the dominant red wood ants. Journal of Animal Ecology, 80, 548-557.

Gibb, H., Sanders, N.J., Dunn, R.R., Photakis, M., Andersen, A.N., Angulo, E. et al. (2015) Climate regulates the effects of anthropogenic disturbance on ant assemblage structure. Proceedings of the Royal Society of London B: Biological Sciences, 282, 20150418.

Giraud, T., Pedersen, J.S. \& Keller, J. (2002) Evolution of supercolonies: The Argentine ants of southern Europe. Proceedings of the National Academy of Sciences of the United States of America, 99, 6075-6079.

Grime, J.P. (1973) Competitive exclusion in herbaceous vegetation. Nature, 242, 244-247.

Grime, J.P. (1979) Plant strategies and vegetation processes. John Wiley, Chichester.

Golberg, D.H., Rajaniemi, T., Gurevitch, J. \& Stewart-Oaten, A. (1999) Empirical approaches to quantifying interaction intensity: competition and facilitation along productivity gradients. Ecology, 80, 1118-1131. 
Hart, S.P. \& Marshall, D.J. (2013) Environmental stress, facilitation, competition, and coexistence. Ecology, 94, 2719-2731.

Hoffmann, B.D., Andersen, A.N. \& Hill, G.J.E. (1999) Impact of an introduced ant on native ra $\mathrm{n}$ forest invertebrates: Pheidole megacephala in monsoonal Australia. Oecologia, 120, 595-604.

Hölldobler, B. (1983) Chemical manipulation, enemy specification and intercolony communication in ant communities. In F. Huber \& H. Markl (Eds.), Neuroethology and Behavioral Physiology (pp. 354-365). Berlin: Springer-Verlag.

Hölldobler, B. \& Wilson, E.O. (1990) The Ants. Belknap Press, Cambridge, MA.

Holway, D.A., Lach, L., Suarez, A.V., Tsutsui, N.D. \& Case, T.J. (2002) The causes and consequences of ant invasions. Annual Review of Ecology, Evolution, and Systematics, 33, $181-233$.

Jenkins, C.N., Sanders, N.J., Andersen, A.N., Arnan, X., Brühl, A., Cerdá, X. et al. (2011) Global diversity in light of climate change: the case of ants. Diversity and Distributions, 17 , $652-662$

King, J.R. \& Tschinkel, W.R. (2006) Experimental evidence that the introduced fire ant, Solenopsis invicta, does not competitively suppress co-occurring ants in a disturbed habitat. Journal of Animal Ecology, 75, 1370-1378.

King, J.R. \& Tschinkel, W.R. (2008) Experimental evidence that human impacts drive fire ant invasions and ecological change. Proceedings of the National Academy of Sciences of the United States of America, 105, 20339-20343.

King, J.R. \& Tschinkel, W.R. (2013) Experimental evidence for weak effects of fire ants in a naturally invaded pine-savanna ecosystem in north Florida. Ecological Entomology, 38, 543545. 
Kneitel, J.M. \& Chase, J.M. (2004) Trade-offs in community ecology: linking spatial scales and species coexistence. Ecology Letters, 7, 69-80.

Lach, L. \& Hooper-Bùi, L.M. (2010) Consequences of Ant Invasions. In L. Lach, C.L. Parr \& K. Abbott (Eds.), Ant Ecology (pp. 261-286). Oxford, UK: Oxford University Press.

Lowe, S., Browne, M., Boudjelas, S. \& Poorter, M. de (2000) 100 of the world's worst invasive alien species - a selection from the global invasive species database.

http://www.issg.org/database/species/reference_files/100English.pdf

MacKey, R.L. \& Currie, D.J. (2001) The diversity-disturbance relationship: is it generally strong and peaked? Ecology, 82, 3479-3492.

kagawa, S. \& Schielzeth, H. (2013) A general and simple method for obtaining R2 from generalized linear mixed-effects models. Methods in Ecology and Evolution, 4, 133-142.

Parr, C.L. (2008) Dominant ants can control assemblages species richness in a South African savanna. Journal of Animal Ecology, 77, 1191-1198.

Parr, C.L., Sinclair, B.J., Andersen, A.N., Gaston, K.J. \& Chown, S.L. (2005) Constraint and competition in assemblages: a cross-continental and modeling approach for ants. American Naturalist, 165, 481-494.

Parr, C.L., Dunn, R.R., Sanders, N.J., Weiser, M.D., Photakis, M., Fitzpatrick, M.C. et al. (2017) GLobal Ants trait Database (GLAD): a new database on the geography of ant traits (Hymenoptera: Formicidae). Insect Conservation and Diversity, 10, 5-20.

Passera, L. (1994) Characteristics of tramp species. In D. Williams (Ed.), Exotic ants: biology, impact and control of introduced species (pp. 23-43). Boulder, CO: Westview Press. Pyšek, P., Jarošík, V., Hulme, P.E., Perg,1 J., Hejda, M., Schaffner, U. \& Vilà. M. (2012). A global assessment of invasive plant impacts on resident species, communities and 
ecosystems: The interaction of impact measures, invading species' traits and environment. Global Change Biology, 18, 1725-1737.

R Core Team (2016). $R$ : A language and environment for statistical computing. $\mathrm{R}$ Foundation for Statistical Computing, Vienna, Austria. URL: https://www.R-project.org/.

Rees, M. (2013) Competition on productivity gradients - what do we expect? Ecology Letters, 16, 291-298.

Ricklefs, R.E. (1987) Community diversity: relative roles of local and regional processes. Science, 235, 167-71.

Room, P.M. (1971) The relative distribution of ant species in Ghana's cocoa farms. Journal of Animal Ecology, 40, 735-751.

Robinson, E.J.H. (2014) Polydomy: the organisation and adaptive function of complex nest systems in ants. Current Opinion In Insect Science, 5, 37-43.

Savolainen, R., Vepsäläinen, K. \& Wuorenrinne, H. (1989) Ant assemblages in the taiga biome: testing the role of territorial wood ants. Oecologia, 81, 481-486.

Silvertown, J., Dodd, M., Gowing, D., Lawson, C. \& McConway, K. (2006) Phylogeny and the hierarchical organization of plant diversity. Ecology, 87, S39-S49.

Slingsby, J.A. \& Verboom, G.A. (2006) Phylogenetic relatedness limits co-occurrence at fine spatial scales: evidence from the schoenoid sedges (Cyperaceae: Schoeneae) of the Cape Floristic Region, South Africa. American Naturalist, 168, 14-27.

Stuble, K.L., Chick, L.D., Rodriguez-Cabal, M.A., Lessard, J-P. \& Sanders, N.J. (2013) Fire ants are drivers of biodiversity loss: a reply to King and Tschinkel (2013). Ecological Entomology, 38, 540-542. 
Stuble, K.L., Juric, I., Cerdá, X., Sanders, N.J. (2017) Dominance hierarchies are a dominant paradigm in ant ecology (Hymenoptera: Formicidae), but should they be? And what is a dominance hierarchy anyways? Myrmecological News, 24, 71-81.

Stubbs, W.J. \& Wilson, J.B. (2004) Evidence for limiting similarity in a sand dune community. Journal of Ecology, 92, 557-567.

Tilman. D. (1982) Resource competition and community structure. Princeton University Press, Princeton, N.J.

Vepsäläinen, K. \& Pisarski, B. (1982) Assembly of island ant communities. Annales Zoologici Fennici, 19, 327-335.

Werner, E.E. (1976) Species interactions in freshwater fish communities. In J. Diamond and . Case (Eds.), Community ecology (pp. 344-357). New York, NY: Harper and Row. 
Table 1. Summary of the best-supported models analyzing the dominance-diversity relationship as well as the relationship between climate and behavioral dominance from different datasets. A reference name for each complete model, the variables included in each complete model, the variables included within the best-fitted models, the range of the rginal and conditional $\mathrm{R}^{2}$ values for the best-fitted models and the number of sites used for each analysis are shown. All complete models included a set of covariates (cov: Continent, Hemisphere, Habitat type, Pitfall days and Transect length). Abbreviations: BD, Behavioral dominance (two levels: sites without dominants and sites with dominants); DT, Dominance type (three levels: sites without dominants, sites with native dominants, and sites with nonnative dominants); MAT, Mean annual temperature; AP, Annual precipitation; RAB, Relative abundance of dominant ants; and S, Species richness.

\begin{tabular}{|c|c|c|c|c|}
\hline Model name & Complete model & Variables selected & $\mathbf{R}_{\text {marginal/conditional }}^{2}$ & $\begin{array}{l}\mathbf{N} \\
\text { sites }\end{array}$ \\
\hline \multicolumn{5}{|c|}{ Effects on species richness } \\
\hline $\begin{array}{l}\text { Global occurrence } \\
\text { model }\end{array}$ & $\begin{array}{l}\mathrm{S}=\mathrm{BD}+\mathrm{MAT}+\mathrm{AP}+ \\
\mathrm{cov}\end{array}$ & $\begin{array}{l}\mathrm{BD}+\mathrm{MAT}+ \\
\text { Hemisphere }\end{array}$ & $\begin{array}{l}0.29-0.34 / 0.66- \\
0.68\end{array}$ & 1293 \\
\hline $\begin{array}{l}\text { Global abundance } \\
\text { model }\end{array}$ & $\begin{array}{l}\mathrm{S}=\mathrm{RAB}+\mathrm{RAB}^{2}+\mathrm{MAT} \\
+\mathrm{AP}+\mathrm{cov}\end{array}$ & $\begin{array}{l}\mathrm{RAB}+\mathrm{RAB}^{2}+ \\
\text { Hemisphere }\end{array}$ & $0.12-0.20 / 0.72$ & 645 \\
\hline $\begin{array}{l}\text { Dominants type } \mathrm{x} \\
\text { climate model }\end{array}$ & $\begin{array}{l}\text { S = DTxMAT + DTxAP } \\
+ \text { DTxMATxAP + cov }\end{array}$ & DTxMAT & $0.35 / 0.69$ & 1293 \\
\hline $\begin{array}{l}\text { Native dominants } \mathrm{x} \\
\text { climate model }\end{array}$ & $\begin{array}{l}S=\text { RABxMAT + } \\
\text { RABxAP + } \\
\text { RABxMATxAP + } \\
\text { RAB }{ }^{2} x M A T+R A B^{2} \times A P \\
+ \text { RAB }^{2} x M A T x A P+\operatorname{cov}\end{array}$ & $\begin{array}{l}\mathrm{RAB}^{2}+\text { Continent }+ \\
\text { Hemisphere }\end{array}$ & $\begin{array}{l}0.04-0.17 / 0.72- \\
0.74\end{array}$ & 523 \\
\hline $\begin{array}{l}\text { Non-native dominants } \\
\mathrm{x} \text { climate model }\end{array}$ & $\begin{array}{l}\mathrm{S}=\mathrm{RABxMAT}+ \\
\mathrm{RABxAP}+\end{array}$ & $\begin{array}{l}\mathrm{RAB}+\mathrm{RAB}^{2}+\text { Habitat } \\
\text { type + Hemisphere }\end{array}$ & $\begin{array}{l}0.17-0.21 / 0.80- \\
0.84\end{array}$ & 122 \\
\hline
\end{tabular}




$$
\begin{aligned}
& \text { RABxMATxAP + } \\
& \mathrm{RAB}^{2} x M A T+\mathrm{RAB}^{2} \mathrm{xAP} \\
& +\mathrm{RAB}^{2} \mathrm{xMAT} x A P+\mathrm{cov}
\end{aligned}
$$

\section{Effects on relative abundance of dominant}

\section{species}

Climate model of

$$
\mathrm{RAB}=\mathrm{MAT}+\mathrm{MAT}^{2}+\quad \mathrm{MAT}+\mathrm{MAT}^{2}+\mathrm{AP}+
$$

0.31-0.37/ 0.54- 523

native dominants

$$
\mathrm{AP}+\mathrm{MATxAP}+\mathrm{cov} \quad \text { Continent }+ \text { Habitat type } 0.59
$$

+ Hemisphere

$\begin{array}{llll}\text { Climate model of } & \mathrm{RAB}=\mathrm{MAT}+\mathrm{MAT}^{2}+ & \text { Continent }+ \text { Habitat type } & 0.11-0.12 / 0.41- \\ \text { non-native dominants } & \mathrm{AP}+\mathrm{MATxAP}+\mathrm{cov} & + \text { Hemisphere } & 0.44\end{array}$




\section{FIGURE LEGENDS}

Figure 1. World map showing the 1293 independent study plots with no dominant ants (green circles), native (yellow circles), or non-native dominants (red circles). Many of the study plots were conducted in independent locations in relatively close proximity, so appear as a single plot.

Figure 2. Relationship between ant species richness and the presence or absence of behaviorally dominant species in the world, and separated by temperate and subtropical and tropical latitudes.

Figure 3. Interaction effects of dominants type (sites without dominants, sites with native dominants and sites with non-native dominants) and mean annual temperature on species richness (ln-transformed) (a), and unimodal relationships between the relative abundance of behaviorally dominant species and ant species richness (ln-transformed) in sites with native or non-native dominant species (blue line), with only native dominants (green line) and sites with only non-native dominants (red line) (b). Shaded area represents the standard error. Circle size is proportional to sample size.

Figure 4. Relationships between mean annual temperature (a) and annual precipitation (b) with the relative abundance (logit transformed) of native dominant species. Shaded area represents the standard error. 

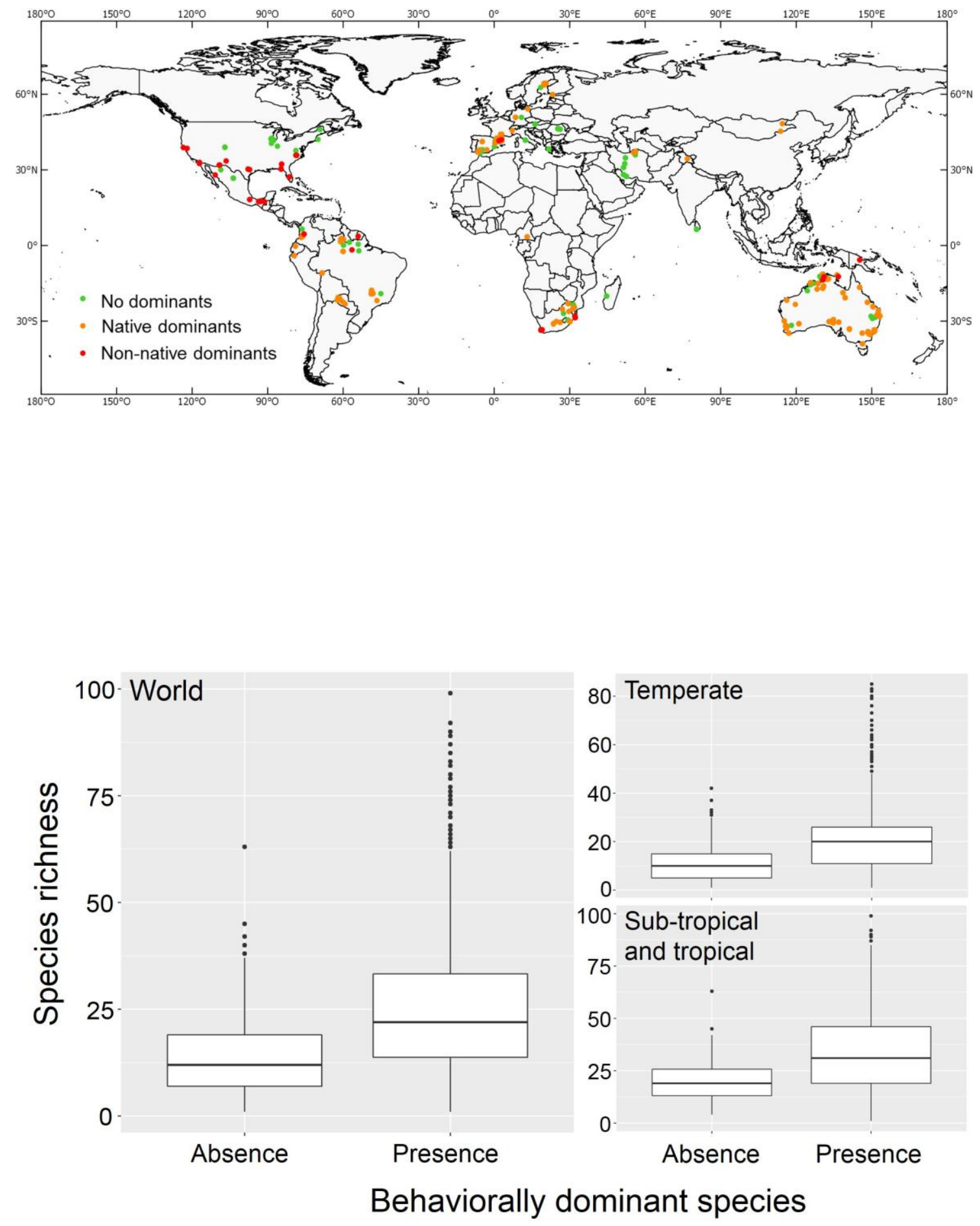
(a)

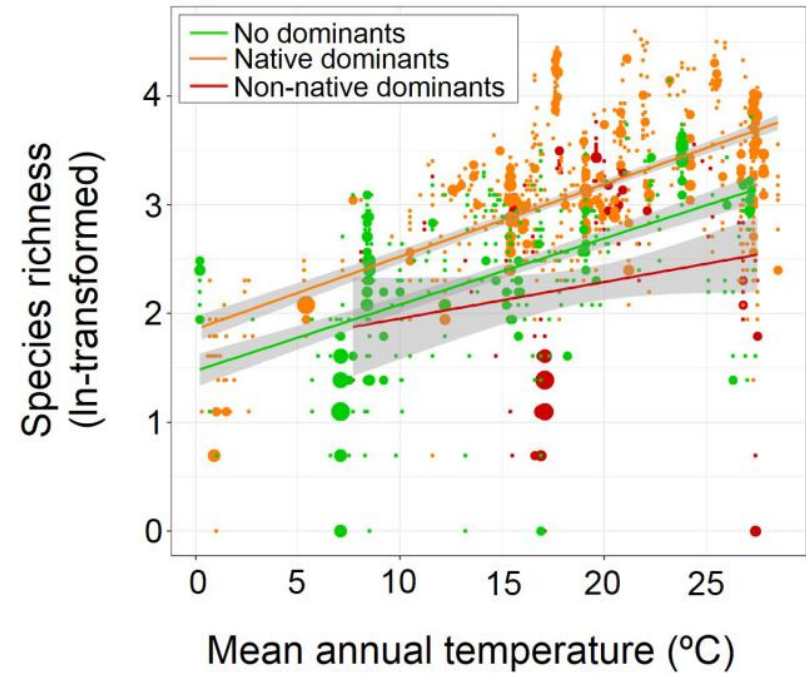

(a)

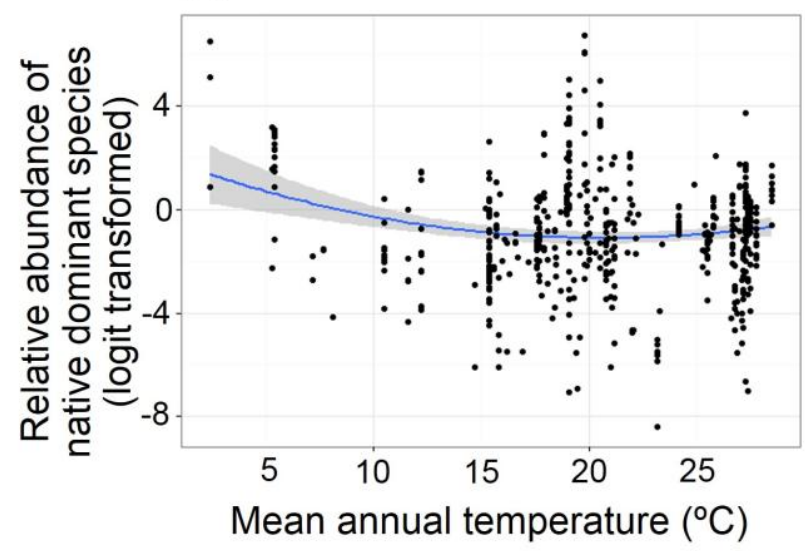

(b)

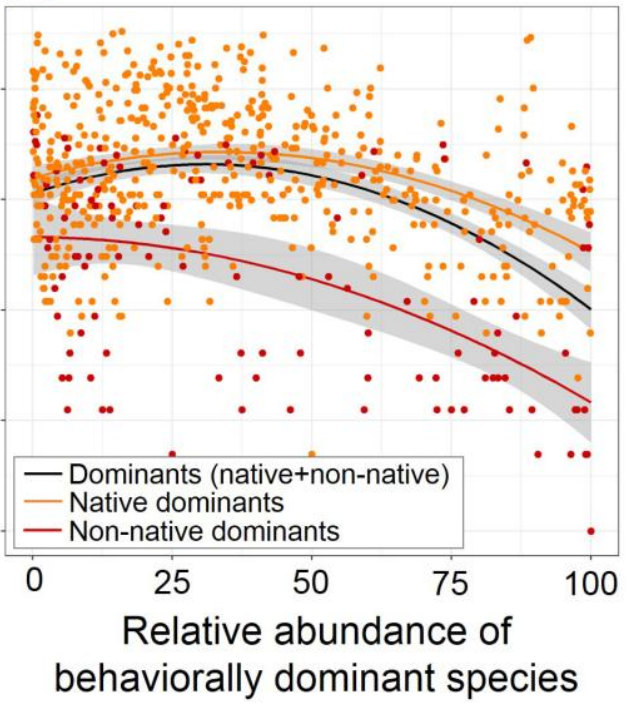

(b)

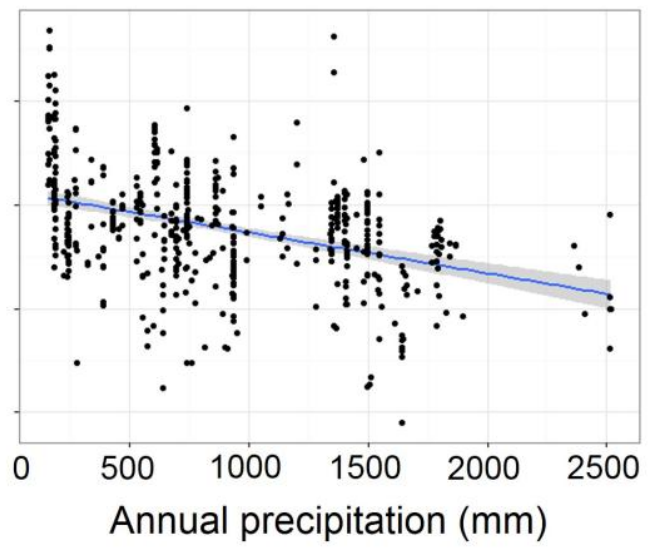

